\title{
MiR-181a and -b expression in acute lymphoblastic leukemia and its correlation with acute graft-versus-host disease after hematopoietic stem cell transplantation, COVID-19 and torque teno viruses
}

\author{
Mahdiyar Iravani Saadi ${ }^{1} \cdot$ Mani Ramzi ${ }^{1,2} \cdot$ Zahra Hesami $^{1} \cdot$ Nadiya kheradmand $^{1}$. \\ Maryam Owjfard $^{3} \cdot$ Ehsan Nabi Abdolyousefi $^{1} \cdot$ Zahed Karimi $^{1,2}$
}

Received: 8 June 2021/Accepted: 14 September 2021/Published online: 25 October 2021

(c) The Author(s), under exclusive licence to Indian Virological Society 2021

\begin{abstract}
Acute lymphoblastic leukemia (ALL), a malignant transformation and proliferation of the lymphoid line of blood cells, is characterized by chromosomal abnormalities and genetic changes. The purpose of this research was the evaluation of expression level of miR-181a and -b in patients with ALL compared to the control group. Furthermore, we examined their expression level in hematopoietic stem-cell transplantation (HSCT) patients who developed acute graft-versus-host disease (aGVHD) in comparison with those without aGVHD and explore the relationship between their expression level and cytogenetic abnormalities. In this cross-sectional study, 76 newly diagnosed adult De novo ALL patients were enrolled who were admitted to our referral hospital. All patients received standard chemotherapy, consisting of daunorubicin. A total of 37 patients underwent HSCT from the related human leukocyte antigen-matched donors. ALL patients have been diagnosed with the coronavirus disease 2019 (COVID-19) and Torque teno viruses (TTVs). We assessed the expression levels of miR-181a and -b in the peripheral blood sample of ALL patients at the time of diagnosis prior to
\end{abstract}

Mani Ramzi

ramzim43@yahoo.com

$\triangle$ Zahed Karimi

zahedkarimi95@yahoo.com

1 Hematology Research Center and Department of Bone Marrow Transplantation, Shiraz University of Medical Sciences, Shiraz, Iran

2 Department of Hematology, Medical Oncology and Stem Cell Transplantation, Shiraz University of Medical Sciences, Shiraz, Iran

3 Clinical Neurology Research Center, Shiraz University of Medical Sciences, Shiraz, Iran chemotherapy, and healthy matched individuals by RTPCR. TTVs and COVID-19 load were also determined via RT-PCR. In conclusion, the expression level of miR-181a and -b were significantly higher in ALL patients than healthy controls and also increased in patients who developed aGVHD in comparison with those without aGVHD. MiR-181a and -b can be a useful biomarker in ALL and a useful indicator of aGVHD. The expression level of miR181a in ALL patients with COVID-19 is significantly upregulated, while it is reduced in these patients with TTV.

Keywords Acute lymphoblastic leukemia - MicroRNAs · aGVHD · COVID-19 - Torque teno viruses

\section{Introduction}

Acute lymphoblastic leukemia (ALL) is a malignant transformation and proliferation of lymphoid progenitor cells, affects not only adults but also children [3]. It is the most common pediatric hematologic tumor, representing over a quarter of all pediatric cancers [42].

Hematopoietic stem cell transplantation (HSCT) is used to treat malignant diseases, particularly hematopoietic malignancies [5]. Acute graft-versus-host disease (aGVHD) is an immunologic event caused by the activation of donor-derived $\mathrm{T}$ cells in response to histocompatibility antigens in the recipient after allogeneic HSCT [39].

MicroRNAs (miRNAs) are a wide class of small $(\sim 22$ nucleotides in length) non-coding RNAs, which are extensively expressed in all metazoan eukaryotes. MiRNAs play an important regulatory role by suppressing the expression of their target genes [4]. To date, few studies have examined the importance of miRNAs in hematopoiesis and more studies are needed. Among the miRNA 
families identified so far, we focused on the miR-181 family. The miR- 181 family is important regulatory molecules in many biological processes including immune response, cell proliferation, apoptosis, mitochondrial function, and autophagy $[54,65]$. It has additionally been noted that the miR-181 family display dual tumor-suppressive [52, 71] and oncogenic functions $[21,27,72,74,77]$. The aberrant expression of the miR181 family has been demonstrated in several hematological cancers derived from lymphoid progenitors, as well as in some myeloid progenitor cells $[22,51]$. Several members of the miR-181 family, mostly miR-181a and -b, have been revealed to functionally regulate the differentiation and development of immune cells and to be involved in the pathogenesis of leukemias [80]. According to research, members of the miR-181 family may be a target for leukemia treatment as well as a useful biomarker in precision medicine [17].

Acute graft-versus-host disease (aGVHD) is an immunologic event caused by the activation of donorderived $\mathrm{T}$ cells in response to histocompatibility antigens in the recipient after allogeneic hematopoietic stem cell transplantation (HSCT) [39].

Several chromosomal abnormalities as one of the causes of ALL have been correlated with leukemic cell lineage, the degree of cell differentiation, and clinical and biologic aspects [18, 59-61]. Findings of cytogenetic abnormalities have prognostic significance because they detect key genes and their protein products that are involved in malignant transformation and proliferation.

Torque teno viruses (TTVs) are members of the Anelloviridae family and have circular, ssDNA genomes that are small $(3.8 \mathrm{~kb})$, which infect humans on a regular basis and cause long-term infections in their host [53]. According to some reports, TTVs use the host miRNA biogenesis machinery to encode biologically active miRNAs, which can either activate or inhibit some intracellular signaling pathways [41].

The extreme acute respiratory syndrome coronavirus 2 causes the coronavirus disease 2019 (COVID-19), which is a worldwide pandemic disease with high mortality rates. Respiratory syndromes and pulmonary diseases caused by viral infections have been linked to dysregulated miRNA expression [6,75]. MiRNAs are involved in the pathogenesis of a wide range of diseases, including viral infections, disease development, and inhibition [41, 53]. According to recent research, host miRNAs play a role in the replication and propagation of viruses and also can directly target both the viral 3'UTR and the coding region of the viral genome to induce antiviral effects $[6,73]$.

In the present study, we compared the expression of miR-181a and -b in patients with ALL compared to the control group. Furthermore, we examined their expression level in HSCT patients who developed aGVHD in comparison with those who did not, and we explored the relationship between their expression level and cytogenetic abnormalities. Our study also provides new insights into the expression analysis of miR-181a and -b in blood samples of ALL patients infected with COVID-19 and TTV.

\section{Materials and methods}

\section{Patients' criteria}

In this cross-sectional study, 76 newly diagnosed adults participated. De novo ALL patients admitted to Namazi hospital for hematological malignancies affiliated to Shiraz University of Medical Sciences between 2019 and 2021 were enrolled. Seventy age-sex matched healthy subjects were also evaluated as normal controls. ALL disease was diagnosed by an expert oncologist, using morphology, cytochemistry, and immunophenotyping. Clinical and laboratory data, including French-American-British (FAB) classifications. Complete blood count, blast percentage, and the concentration of hemoglobin $(\mathrm{Hb})$ level were also measured. All patients received standard chemotherapy in the form of cycles A and B. Cycle A: cyclophosphamide $300 \mathrm{mg} / \mathrm{m}^{2}$ intravenously (IV) every $12 \mathrm{~h}$ for 6 doses on day 1,2 , and 3 , Mesna IV $1200 \mathrm{mg} / \mathrm{m}^{2} /$ day as a continuous IV infusion on day 1,2 , and 3 , Vincristine $1.4 \mathrm{mg} / \mathrm{m}^{2} /$ day IV on day 4 and 11 , Doxorubicin $50 \mathrm{mg} / \mathrm{m}^{2} /$ day on day 4 , Dexamethasone $40 \mathrm{mg} /$ day on days 1-4 and 11-14. Cycle B: methotrexate $1 \mathrm{~g} / \mathrm{m}^{2}$ as a continuous infusion on day 1 , Leuocoverin $15 \mathrm{mg}$ every $6 \mathrm{~h}$ for 8 doses, starting $12 \mathrm{~h}$ after the end of methotrexate infusion, Cytarabine $3 \mathrm{~g} / \mathrm{m}^{2}$ every $12 \mathrm{~h}$, for 4 doses on days 2 and 3 [36]. Demographic and clinical variables included age at diagnosis, gender, white blood cells (WBC) count, hemoglobin and lactate dehydrogenase (LDH) levels, and platelet count. A total of 37 patients received hematopoietic stem cell transplantation (HSCT) from the related human leukocyte antigen (HLA)-matched donors. Moreover, aGVHD was classified using the classic Glucksberg-Seattle criteria and the International Bone Marrow Transplant Registry [24, 78]. Grade 1 is mild GvHD. It means up to a quarter $(25 \%)$ of patient's skin is affected. Grade 2 is moderate GvHD. It means up to half patient's skin (25 to $50 \%$ ) is affected. There are mild changes in patient's liver or may have some mild diarrhoea or feel sick. Grade 3 is severe GvHD. It means more than half patient's skin (over 50\%) is affected. It may look as though patients have severe sunburn. patient's liver is affected and have stomach cramps and diarrhoea. Grade 4 is very severe GvHD. patient's skin has blistered and may have broken down in places. Patient's 
skin may be yellow (jaundiced) because of liver is not working properly and patients have severe diarrhea $[24,66]$. All procedures were carried out in accordance with the 1975 Helsinki Protocol and its subsequent amendments. It was also approved by the Ethics Committee of Shiraz University of Medical Sciences (SUMS, Ethical code: IR.SUMS.REC.1396-01-32-15,396).

\section{Cytogenetic analysis}

The karyotype was determined using the standard G-banding technique. Reverse transcriptase-polymerase chain reaction (RT-PCR) was used to look for chromosomal abnormalities in BCR/ABL, TEL/AML1, and E2A/ PBX1. Patients' cytogenetic results were classified as abnormal or normal. Patients who tested negative for these chromosomal abnormalities were considered cytogenetic normal.

\section{Sample collection and ribonucleic acid isolation}

Each patient, as well as healthy individuals, had five milliliters of peripheral blood collected in Ethylenediaminetetraacetic acid (EDTA)-containing tubes at the time of diagnosis prior to chemotherapy. Ficoll-hypaque density gradient centrifugation was used to isolate peripheral blood mononuclear cells (PBMCs) from each patient and control. As previously described, total RNA was extracted using the TRIZOL reagent (Invitrogen) according to the manufacturer's instructions. [31, 32, 67].

\section{Quantification of the miR-181a and -1b mRNAs expression level by SYBR green real-time PCR}

In accordance with the manufacturer's instructions, complementary DNA (cDNA) was transcribed, using SuPrime Script RT Premix (2X) cDNA Synthesis Kit (GeNet BIO Inc; Daejeon, South Korea). The SYBR Green Real-Time PCR method was used to quantify the expression of miR181a and -b mRNAs using SYBR Premix Ex Taq TM II (Tli RNaseH Plus) (Takara, Japan) according to the manufacturer's instructions, as previously described [31, 32, 67]. In expression studies, GAPDH was used as an internal control. Real-Time PCR method was performed by iQ5 thermocycler (BioRad Laboratories, USA). The primers were designed for each miRNA using free software such as Beacon Designer 7 and AlleleID (version 7.5) and also checked by Primer-BLAST and listed in Table 1.

\section{Molecular detection of TTV and COVID-19 infection}

The TTV infection was analyzed using the PCR method. Briefly, the TTV genomic DNA was extracted from blood using a dinitrophenol kit (Cinna Gen Inc., Tehran, Iran) according to manufacturer instruction. The presentation of TTV genomic DNA was analyzed in ALL patients using an in-house semi-nested-PCR protocol, as previously described [35, 38, 62].

Throat swab samples or deep nasal cavity swab samples were collected for extracting COVID-19 RNA from patients suspected of having COVID-19 infection. The collected swabs were placed into a collection tube with $2 \mathrm{ml}$ of virus transfer media, and total RNA was extracted using QIAamp ${ }^{\mathrm{TM}}$ viral RNA mini kit from Qiagen ${ }^{\mathrm{TM}}$ according to the manufacturer's instructions. The COVID19 load was determined for all samples via Real-time PCR by COVID-19 kit (BXM, Iran), according to the manufacturer's instruction [12].

\section{Statistical analysis}

Data were analyzed by SPSS software, version 18. The differences in the mean expression level of miR-181a and $\mathrm{b}$ between patients and controls as well as patients according to response to chemotherapy and FAB subtypes were compared via independent t-test. The association between the mean expression of the miR-181a and -b and laboratory data were analyzed by Pearson correlation test.

\section{Results}

Of 76 newly diagnosed ALL patients, 53 (69.7\%) were male and $23(30.3 \%)$ were female. The mean age of ALL patients was $41 \pm 1.6$ with a range of $15-67$ years. The laboratory characteristics of patients with ALL displayed that the mean WBC count at diagnosis was $50,041 \pm 90,351 / \mathrm{cm}$. The average platelet count was $51,238 \pm 6361 / \mathrm{mL}$ and the mean $\mathrm{Hb}$ and $\mathrm{LDH}$ levels in these patients were $9.3 \pm 0.53 \mathrm{~g} / \mathrm{dL}$ and $1871 \pm 196 \mathrm{U} / \mathrm{L}$, respectively. Markers were compared against normal ranges. ALL patients present with a very high white blood cell count, which is called leukocytosis, however, the platelet count and $\mathrm{Hb}$ are critically low (Table 2).

Sixteen patients developed aGVHD, with seven developing low grade (grade I + II) aGVHD and nine developing high grade (grade III + IV) aGVHD. 
Table 1 The Primer sequences for qRT-PCR and PCR condition used for the miR-181a and -b and GAPDH gene

\begin{tabular}{lll}
\hline Gene & Primer sequences & Thermocycling condition \\
\hline GAPDH & $\begin{array}{l}\text { Forward GGACTCATGACCACAGTCCA } \\
\text { Reverse CCAGTAGAGGCAGGGATGAT }\end{array}$ & $95{ }^{\circ} \mathrm{C} / 2 \mathrm{~min}, 40$ cycles of $95{ }^{\circ} \mathrm{C} / 30 \mathrm{~s}, 57.5{ }^{\circ} \mathrm{C} / 20 \mathrm{~s}$ and $70{ }^{\circ} \mathrm{C} / 30 \mathrm{~s}$ \\
MIR-181a & $\begin{array}{l}\text { Forward ACTGACAACATTCAACGCTGTCG } \\
\text { Reverse GTGCAGGGTCCGAGGT }\end{array}$ & $94{ }^{\circ} \mathrm{C} / 2 \mathrm{~min}, 40$ cycles of $94{ }^{\circ} \mathrm{C} / 30 \mathrm{~s}, 58{ }^{\circ} \mathrm{C} / 20 \mathrm{~s} \mathrm{and} 70{ }^{\circ} \mathrm{C} / 30 \mathrm{~s}$ \\
MIR-181b & $\begin{array}{l}\text { Forward GTTTGAACATTCATTGCTGTCG } \\
\text { Reverse GTGCAGGGTCCGAGGT }\end{array}$ & $95{ }^{\circ} \mathrm{C} / 2 \mathrm{~min}, 40$ cycles of $95{ }^{\circ} \mathrm{C} / 30 \mathrm{~s}, 60{ }^{\circ} \mathrm{C} / 20 \mathrm{~s}$ and $70{ }^{\circ} \mathrm{C} / 30 \mathrm{~s}$ \\
& & \\
\hline
\end{tabular}

Table 2 Laboratory data of ALL patients

\begin{tabular}{lc}
\hline Variable & Mean $\pm \mathrm{SD}$ \\
\hline WBC count & $50,041 \pm 90,351$ \\
PLT count & $51,238 \pm 6361$ \\
$\mathrm{Hb}(\mathrm{g} / \mathrm{dL})$ & $9.3 \pm .53$ \\
$\mathrm{LDH}(\mathrm{U} / \mathrm{L})$ & $1871 \pm 196$ \\
\hline
\end{tabular}

\section{Aberrant miR-181a and -b expression in ALL patients}

The mRNA expression of miR-181a and -b was compared between ALL patients and controls. After the statistical analysis, our results revealed that the expression of miR$181 \mathrm{a}$ and $-\mathrm{b}$ in these patients were significantly higher (4.8 and 3.8 fold, respectively) in ALL patients than healthy controls $(3.2 \pm 0.52$ vs. $4.5 \pm 0.98, * P=0.001$ and $1.9 \pm 0.13$ vs. $5.6 \pm 0.64, * P=0.002$, respectively, Fig. 1).

\section{The relationship of $\mathrm{miR}-181 \mathrm{a}$ and $-\mathrm{b}$ expression level and $T$ and $B$ cells in ALL patients}

In this study, we evaluated the expression of the miR-181a and $-\mathrm{b}$ attributed to $\mathrm{T}$ and $\mathrm{B}$ cells in ALL patients. Our

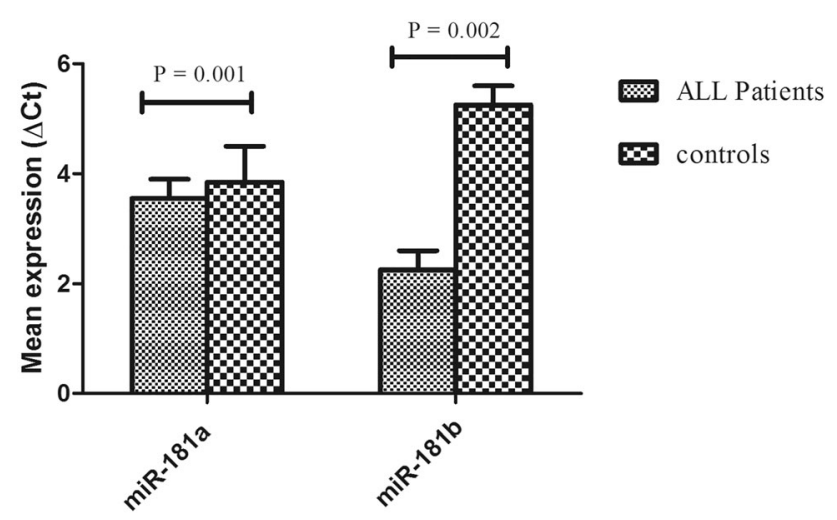

Fig. 1 The expression levels of MiR-181a and MiR-181b in acute lymphoblastic leukemia (ALL) patients compared to control. Results are shown as the mean expression values and statistical significance was determined using an unpaired Student's t test results showed that the miR-181a and $-b$ expression attributed to $\mathrm{T}$ cell was significantly higher than $\mathrm{B}$ cell in patients with ALL $(2.4 \pm 0.87$ vs. $6.7 \pm 2.3 ; P=0.05$ and $1.2 \pm 0.31$ vs. $2.6 \pm 0.66 ; \quad P=0.001, \quad$ respectively, Fig. 2).

\section{MiR-181a and -b expression level in HSCT patients who developed aGvHD}

The mean expression level of miR-181a and -b were compared between hematopoietic stem-cell transplantation (HSCT) patients who developed aGVHD and those that did not develop aGVHD. Our results revealed that the expression of miR-181a was higher in patients who developed aGVHD in comparison with those without aGVHD, although this increase was not statistically significant $(P>0.05)$. However, our results demonstrated that miR-181b expression level was significantly increased in patients who developed aGVHD in comparison with those without aGVHD $(2.7 \pm 0.84$ vs. $3.4 \pm 1.05 ; P=0.01)$. In addition, miR-181a and -b were overexpressed in HSCT patients with high-grade aGVHD (grade III-IV) compared to those patients who developed low grade (grade 0-II),

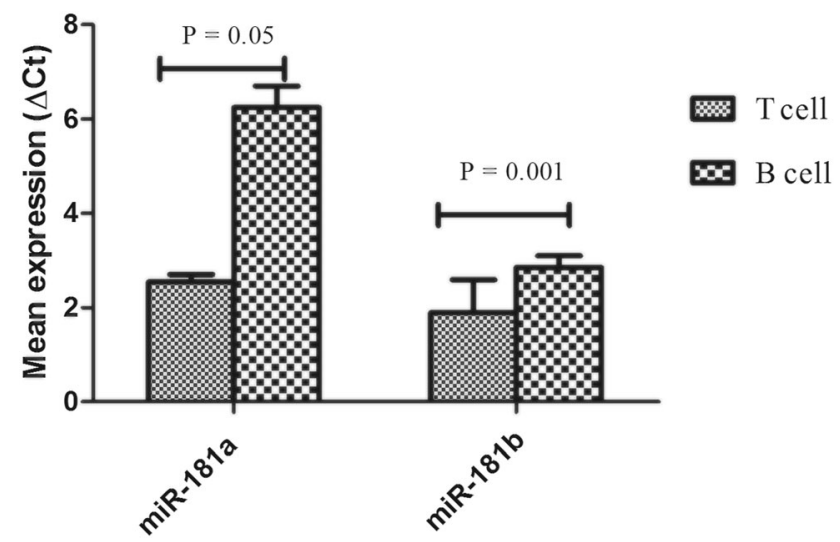

Fig. 2 The relative change in MiR-181a and MiR-181b expression with $\mathrm{T}$ and $\mathrm{B}$ cells in acute lymphoblastic leukemia patients. Results are shown as the mean expression values and statistical significance was determined using an unpaired Student's t test 
although the difference was not statistically significant $(-0.2 .3 \pm 2.1$ vs. $1.6 \pm 0.99 ; P=0.9$ for miR-181a and $2.5 \pm 1.7$ vs. $3.4 \pm 2.7 ; P=0.5$ for miR-181b, Fig. 3).

\section{MiR-181a and -b expression level according to cytogenetic status}

In this study, we show cytogenetic findings on ALL patients, and the details of these abnormalities are provided in Table 2. Among 76 ALL patients, 52 had normal cytogenetic and 24 had abnormal karyotype. Furthermore, the expression level of miR-181a and -b was compared within ALL patients based on their cytogenetic abnormalities. Our results showed that the expression level of miR-181a was significantly increased in $\mathrm{t}(9 ; 22) \mathrm{BCR} / \mathrm{ABL}$ cytogenetic abnormalities $(P=0.03)$. However, we did not find significant differences in the expression level of miR-181a and $-\mathrm{b}$ between patients who carried $\mathrm{t}(12 ; 21) \mathrm{TEL} / \mathrm{AML} 1$ and $\mathrm{t}(1 ; 19) \mathrm{E} 2 \mathrm{~A} / \mathrm{PBX} 1$ and patients without this abnormality $(P>0.05)$ (Table 3$)$.

\section{Association of MiR-181a and miR-181b expression with TTV infection in ALL patients}

TTV was detected in 14 of $76(18.4 \%)$ patients. The mean expression of MiR-181a and MiR-181b were compared in patients according to the TTV infection status (Fig. 4). MiR-181a and -b gene expression levels were less in $\mathrm{TTV}^{+}$ patients compared to $\mathrm{TTV}^{-}$patients, albeit our results demonstrated that only miR-181a expression level was significantly decreased in $\mathrm{TTV}^{+}$patients in comparison TTV $^{-}$patients $(P=0.001)$.

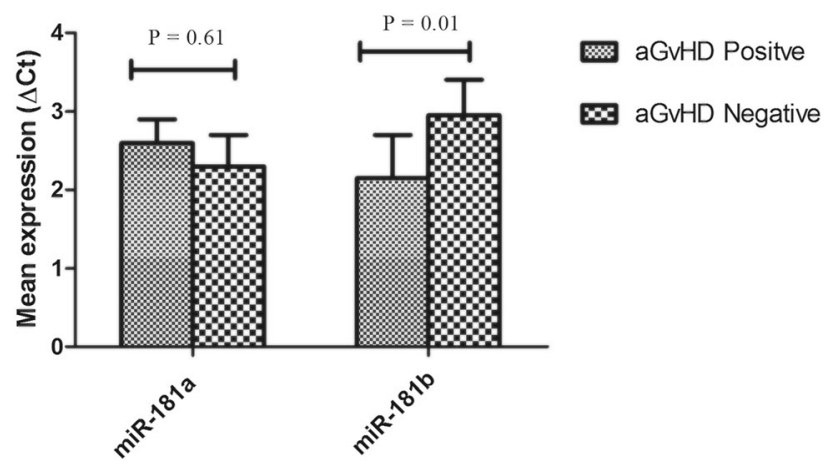

Fig. 3 The expression levels of MiR-181a and MiR-181b in acute lymphoblastic leukemia patients underwent hematopoietic stem-cell transplantation (HSCT) who developed aGVHD compared to those that did not develop aGVHD. Results are shown as the mean expression values and statistical significance was determined using an unpaired Student's t test
Table 3 Acute lymphoblastic leukemia with recurrent cytogenetic abnormalities

\begin{tabular}{ll}
\hline Cytogenetic abnormalities & No. of patients $(\%)$ \\
\hline $\mathrm{t}(9 ; 22) \mathrm{BCR} / \mathrm{ABL}$ & $14(18.4 \%)$ \\
$\mathrm{t}(12 ; 21)$ TEL/AML1 & $6(7.8 \%)$ \\
$\mathrm{t}(1 ; 19) \mathrm{E} 2 \mathrm{~A} / \mathrm{PBX} 1$ & $4(5.2 \%)$ \\
\hline
\end{tabular}

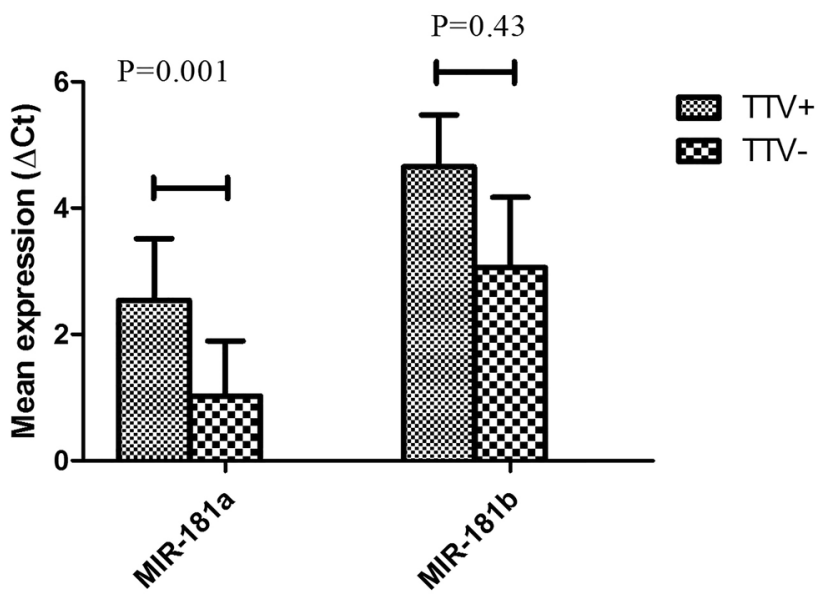

Fig. 4 The relative change in MiR-181a and MiR-181b expression with TTV infection in acute lymphoblastic leukemia patients

\section{Association of miR-181a and miR-181b expression with COVID-19 infection in ALL patients}

COVID-19 infection was detected in 5 of $76(6.5 \%)$ ALL patients. Figure 5 shows the baseline expression levels of MiR-181a and - $b$ in ALL patients according to the COVID19 infection status. Our results demonstrated that MiR181a and -b expression levels were increased in COVID$19^{+}$patients compared to COVID-19- $9^{-}$patients, albeit just miR-181a expression level was significantly increased in

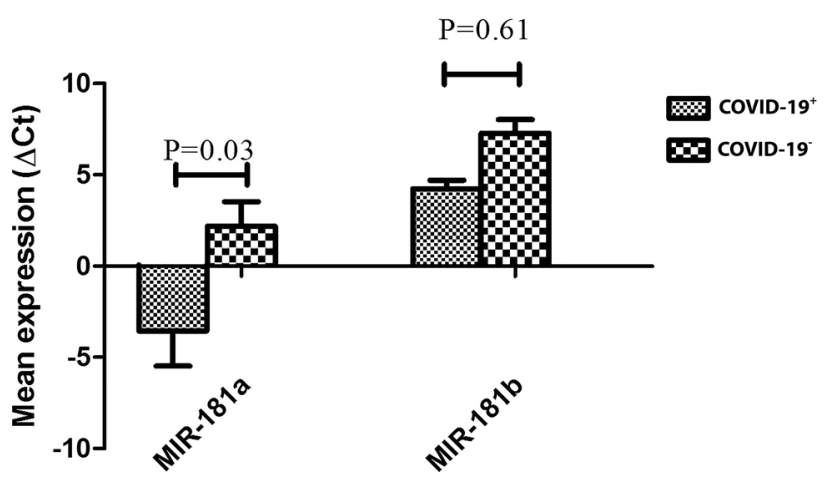

Fig. 5 The relative change in MiR-181a and -b expression with COVID-19 infection in acute lymphoblastic leukemia patients 
COVID- $19^{+}$patients in comparison COVID-19 ${ }^{-}$patients $(P=0.03)$.

\section{Discussion}

ALL is a malignant neoplasm that can affect both adults and children [3]. HSCT is one of the most common treatments for hematopoietic malignancies. Infection and aGvHD are serious cause of morbidity and mortality, as well as a negative outcome following HSCT [11, 84]. Several studies have highlighted aberrantly expressed miRNAs in patients with ALL [7]. The miRNAs are a class of non-coding, single-stranded RNAs composed of approximately 22 nucleotides, that function as post-transcriptional negative regulators of gene expression. MiRNAs appear to be important regulators in tumorigenesis and drug resistance $[34,40]$. In the present study, 76 newly diagnosed adult patients with ALL were given standard daunorubicin-based induction chemotherapy. A total of 37 patients underwent HSCT during the study period, with only Sixteen patients developed aGVHD. The aim of this study was to compare the expression levels of miR-181a and $-b$ in these patients to the normal population. Furthermore, we compared the expression levels of these genes in HSCT patients who experienced aGVHD to those who did not, as well as the association between their expression levels and cytogenetic abnormalities. In addition, we measured the expression levels of miR-181a and b in blood samples from ALL patients with COVID -19 and TTV infection. The expression of miRNAs in different diseases has gotten a lot of attention and a lot of studies has found connections between changes in miRNA homeostasis and pathological conditions like cancer [43, 49]. The miR-181 family, which is primarily expressed in neuronal, blood, and lymphoid tissues, controls cell proliferation, apoptosis, mitochondrial function, and immune response $[10,54,65]$. The anomalous expression of the miR-181 family has been reported in several hematological cancers [57]. Several members of this family, mostly miR-181a and -b have been implicated in the etiopathogenesis of hematological tumors and malignancies [80]. For example, a study found that patients with B-cell chronic lymphocytic leukemia had abnormal expression of several members of the miR-181 family (mostly miR-181a and b) [57]. Alterations in the expression of miRNAs can be considered as biomarkers for the prognosis, diagnosis, classification, and treatment of cancer, although understanding how miRNAs affect the pathogenesis of cancer is complicated [8]. miR181a had different expression levels in different hematological malignancies. Since members of the miR181 family play different roles in hematological malignancies, they may be used as part of a precision medicine approach to cancer treatment. It is up-regulated in AML and myelodysplastic syndromes [58], but downregulated in multiple myeloma and chronic lymphocyte leukemia [37]. Our findings revealed that the expression of miR-181a and -b was significantly higher in ALL patients compared to healthy controls, suggesting that miR-181a and -b may be a useful biomarker. Our findings are consistent with previous research that has shown an increase in miR-181a expression in acute myeloid leukemia (AML) [14, 48, 56]. In pediatric ALL, miR-181a has also been shown to have a role in leukemogenesis and to be significantly overexpressed in T-cell leukemia. Besides, the expression of miR181a decreased significantly after a 6-month therapeutic period [16]. miR-181b was found to be highly expressed in AML and to induce cell proliferation, which is crucial in the progression of AML [9]. However, according to other studies, miR-181b is down-regulated in chronic lymphocytic leukemia as compared to the normal control that was in contrast with our findings regarding the expression of miR-181b in ALL patients [79, 80]. Moreover, patients with chronic myeloid leukemia had significantly lower expression levels of miR-181a and -b [81]. Up-regulation of miR-181 family has been found in patients with inflammatory responses, and has been demonstrated to decrease inflammatory factor expression or inhibit inflammatory response, which may be beneficial in leukemia situations [82, 83, 85]. Some studies have also suggested their tumor suppressor role for these miRNAs [80]. Furthermore, miR-181a and -b are known to play a key regulatory role in lymphoid cell growth, differentiation, and function $[45,76]$ and proposed that their specific expression profiles are associated with the different steps of the maturation and differentiation process [25, 26]. In this regard, a recent study reported that miR-181a over expression inhibited leukemia cell proliferation, apoptosis, and increased the remission rate in children with ALL [15]. Overexpression of miR-181 has been linked to cell proliferation and is thought to play a role in tumorigenesis and cancer progression. Previous research suggests that overexpression of miR-181 promotes cell proliferation via the PI3K/AKT signaling pathway [20, 28]. MiR-92a and miR181a are upregulated in newly diagnosed AML patients, according to our previous study [68]. We showed for the first time that the c-Kit gene may be a new target gene for miR-92a and miR-181a [31, 67]. The difference is probably attributed to the phase of lymphocytic leukemia (acute $v s$. chronic) and type of leukemia.

Patients may be classified into groups based on the cell of origin like B-cell leukemia and T-cell leukemia. Our results showed that the expression level of miR-181a and $\mathrm{b}$ attributed to $\mathrm{T}$ cell was significantly higher than $\mathrm{B}$ cell in patients with ALL. B-cell has been reported to have a better survival than T-cell lymphoblastic leukemia [47]. 
According to numerous studies, circulating microRNAs exhibit changed expression level during the start of aGvHD and can be used as predictive and diagnostic biomarkers [13]. Our results also demonstrated that miR-181a and -b expression levels were significantly higher in patients who developed aGVHD compared to those who did not; however, this increase was only statistically significant for miR-181b expression levels. The results also showed that the higher the aGVHD grade, the higher the expression level of the miR-181a and -b. This finding revealed that both miR-181a and -b (especially miR-181b) play an important role in the development of aGVHD and the miR181a and -b level could be used as an indicator of aGVHD, replicating the severity of the disease. Contrary to our findings, several studies have reported that miR-181a were significantly downregulated at aGvHD diagnosis compared to patients who remained aGvHD free, and that miR-181a functioned as a reliable predictive marker of aGVHD. They explained the reason for the action of this microRN as its regulatory role in the level of cytokines involved in the pathophysiology of aGVHD [13, 44, 69].

Numerous studies have shown that cytogenetic abnormalities such as $t(9,22)$ BCR-ABL, $t(12 ; 21)$ TEL/AML1 and $t(1 ; 19)$ E2A/PBX1 are pathognomonic in ALL patients and serve as strong prognostic tool [1,33]. Our results displayed the expression level of miR-181a was significantly up-regulated in BCR/ABL cytogenetic abnormalities; implying that it could be used as a prognostic marker and therapeutic target. These findings were in accordance previous research that suggests the miR-181 family could be a potential target for cancer treatment $[30,63]$. Besides, we did not observe a significant change in the expression level of miR-181a and -b in ALL patients who carried TEL/AML1 and E2A/PBX1. The findings and analysis show a correlation between miR-181a and -b levels and ALL pathogenesis. Unfortunately, not many studies have been done to compare with our results, but according to numerous studies, increased expression levels of miR-181 has also been linked to a better clinical outcome in cytogenetically normal [50, 70] and abnormal [46] acute myeloid leukemia.

Many studies have shown that the rate of TTV viremia is higher in immunosuppressed individuals, such as cancer patients and transplant recipients $[29,55]$. In the present study, the TTV was diagnosed in $18.4 \%$ of ALL patients. Recent studies have therefore suggested that TTV viremia could be a biomarker to assess immune function [19, 64]. Several studies have recently looked into the TTV family for the ability to encode miRNAs which target transcripts of their host cell. TTVs encode a wide range of viral miRNAs, and their interactions with the host miRNA biogenesis pathway have been investigated [41]. We demonstrated an inhibitory role for a TTV miRNA in miR- 181a expression level in ALL patients that have increased in these patients. Our findings bring new insights into the TTV and its interactions with the host miRNA machinery.

COVID-19, a pandemic infection, causes severe acute respiratory syndrome and pulmonary diseases. Near the end of 2019, a new COVID-19 was discovered, causing a variety of symptoms including fever, cough, heavy pneumonia, and in some cases, death. After its discovery in Wuhan, China, the pathogen has been known as COVID-19 and it quickly became a global pandemic [23]. According to new findings, both the viral 3'UTR and the coding region of the viral genome can be specifically targeted by host cellular miRNAs to induce antiviral effects $[6,41]$. Several studies have found that host miRNAs (miR-323, miR-491, miR-485, miR-654, and miR-3145) bind to the coding region of the influenza PB1 gene, degrade RNA, inhibit viral translation, and decrease viral particle accumulation [2]. Furthermore, human immunodeficiency virus type 1 (HIV-1) nef protein expression is inhibited by host cellular miRNA-29a, which inhibits viral replication [55]. On the other hand, several studies have indicated that host miRNAs have a beneficial effect on viral replication. For example, MiR-122 binds to the 3' and 5' UTRs of hepatotropic virus RNA, increasing viral RNA stability and allowing viral propagation [6, 29, 41]. Based on the above papers, we performed a study of miRNAs targeting SARS and COVID-19 (recent isolates from various regions) to better understand the pathophysiology and find new therapeutic targets. In the present study, the COVID-19 was found in 6.5 percent of ALL patients. MiRNAs have the potential to affect the expression of certain genes, and treatment based on them has great potential in future medicine. The majority of miRNA studies in connection with COVID-19 have been performed. In our study, we discovered that miR-181a expression level was significantly higher in ALL patients with COVID- $19^{+}$in comparison COVID-19- indicating the pathological role and prognostic impact of miR-181 in ALL patients with COVID- $19^{+}$.

In conclusion, we found that miR-181a and $-\mathrm{b}$ were overexpressed in ALL patients compared to normal populations, suggesting that it could be a useful biomarker. MiR-181a and -b may play an important role in the pathogenesis of aGVHD and can be used as an indicator of aGVHD. The expression of miR-181a is significantly increased in ALL patients with COVID- $19^{+}$, whereas it is decreased in these patients with $\mathrm{TTV}^{+}$.

Funding Funding was provided by Shiraz University of Medical Sciences (Grant No. 1396-01-32-15396). 


\section{References}

1. Alqasi A, Tavakolifar Y, Rezaeeyan H, Saki N, Bagherpour S, Nasab MA. Cytogenetic and molecular assessment of childhood acute lymphoblastic leukemia patients from 2014 to 2017 in Ahvaz. Clin Cancer Investig J. 2019;8:28.

2. Arroyo JD, Chevillet JR, Kroh EM, Ruf IK, Pritchard CC, Gibson DF, Mitchell PS, Bennett CF, Pogosova-Agadjanyan EL, Stirewalt DL. Argonaute 2 complexes carry a population of circulating microRNAs independent of vesicles in human plasma. Proc Natl Acad Sci. 2011;108:5003-8.

3. Bahrebar M, Chalak T. The association of apolipoprotein A1 gene polymorphisms with acute lymphocytic leukemia in Tehran province. Jentashapir J Cell Mol Biol. 2020;11:e106563.

4. Bartel DP. MicroRNAs: genomics, biogenesis, mechanism, and function. Cell. 2004;116:281-97.

5. Bernasconi P, Borsani O. Immune escape after hematopoietic stem cell transplantation (HSCT): from mechanisms to novel therapies. Cancers. 2020;12:69.

6. Bruscella P, Bottini S, Baudesson C, Pawlotsky J, Feray C, Trabucchi M. Viruses and miRNAs: more friends than foes. Front Microbiol. 2017;8(2017):824.

7. Burke MJ, Bhatla T. Epigenetic modifications in pediatric acute lymphoblastic leukemia. Front Pediatr. 2014;2:42.

8. Calin GA, Croce CM, editors. Genomics of chronic lymphocytic leukemia microRNAs as new players with clinical significance. Seminars in oncology. Amsterdam: Elsevier; 2006.

9. Chen H, Chen Q, Fang M, Mi Y. microRNA-181b targets MLK2 in HL-60 cells. Sci China Life Sci. 2010;53:101-6.

10. Chen C-Z, Li L, Lodish HF, Bartel DP. MicroRNAs modulate hematopoietic lineage differentiation. Science. 2004;303:83-6.

11. Cho S-Y, Lee H-J, Lee D-G. Infectious complications after hematopoietic stem cell transplantation: current status and future perspectives in Korea. Korean J Intern Med. 2018;33:256-76.

12. Corman VM, Landt O, Kaiser M, Molenkamp R, Meijer A, Chu DK, Bleicker T, Brünink S, Schneider J, Schmidt ML, Mulders DG, Haagmans BL, van der Veer B, van den Brink S, Wijsman L, Goderski G, Romette JL, Ellis J, Zambon M, Peiris M, Goossens H, Reusken C, Koopmans MP, Drosten C. Detection of 2019 novel coronavirus (2019-nCoV) by real-time RT-PCR. Euro Surveill Bull Europeen sur les maladies transmissibles Eur Commun Dis Bull. 2020;25:2000045.

13. Crossland RE, Norden J, Juric MK, Green K, Pearce KF, Lendrem C, Greinix HT, Dickinson AM. Expression of serum microRNAs is altered during acute graft-versus-host disease. Front Immunol. 2017;8:308.

14. Debernardi S, Skoulakis S, Molloy G, Chaplin T, Dixon-McIver A, Young B. MicroRNA miR-181a correlates with morphological sub-class of acute myeloid leukaemia and the expression of its target genes in global genome-wide analysis. Leukemia. 2007;21:912-6.

15. Desoky AE, Badrawy H, Razik DIAE, Riad KF, Abdelhamid ON, Hassan E. Predictive value of miRNA-181a in pediatric acute lymphoblastic leukemia. J Cancer Ther. 2020;11:673-82.

16. Duyu M, Durmaz B, Gunduz C, Vergin C, Yilmaz Karapinar D, Aksoylar S, Kavakli K, Cetingul N, Irken G, Yaman Y, Ozkinay F, Cogulu O. Prospective evaluation of whole genome microRNA expression profiling in childhood acute lymphoblastic leukemia. BioMed Res Int. 2014;2014:967585.

17. Egyed B, Kutszegi N, Sági JC, Gézsi A, Rzepiel A, Visnovitz T, Lórincz P, Müller J, Zombori M, Szalai C, Erdélyi DJ, Kovács GT, Semsei ÁF. MicroRNA-181a as novel liquid biopsy marker of central nervous system involvement in pediatric acute lymphoblastic leukemia. J Transl Med. 2020;18:250.
18. Faderl S, Kantarjian HM, Talpaz M, Estrov Z. Clinical significance of cytogenetic abnormalities in adult acute lymphoblastic leukemia. Blood. 1998;91:3995-4019.

19. Focosi D, Antonelli G, Pistello M, Maggi F. Torquetenovirus: the human virome from bench to bedside. Clin Microbiol Infect. 2016;22:589-93.

20. Fragoso R, Mao T, Wang S, Schaffert S, Gong X, Yue S, Luong R, Min H, Yashiro-Ohtani Y, Davis M, Pear W, Chen CZ. Modulating the strength and threshold of NOTCH oncogenic signals by mir-181a-1/b-1. PLoS Genet. 2012;8:e1002855.

21. Gao W, Yu Y, Cao H, Shen H, Li X, Pan S, Shu Y. Deregulated expression of miR-21, miR-143 and miR-181a in non small cell lung cancer is related to clinicopathologic characteristics or patient prognosis. Biomed Pharmacother. 2010;64:399-408.

22. Ghiotto F, Fais F, Valetto A, Albesiano E, Hashimoto S, Dono M, Ikematsu H, Allen SL, Kolitz J, Rai KR. Remarkably similar antigen receptors among a subset of patients with chronic lymphocytic leukemia. J Clin Investig. 2004;113:1008-16.

23. Ghodbane S, Lahbib A, Ammari M, Sakly M, Abdelmelek H. Does static magnetic field-exposure induced oxidative stress and apoptosis in rat kidney and muscle? Effect of vitamin $\mathrm{E}$ and selenium supplementations. Gen Physiol Biophys. 2014;34:23-32.

24. Glucksberg H, Storb R, Fefer A, Buckner CD, Neiman PE, Clift RA, Lerner KG, Thomas ED. Clinical manifestations of graftversus-host disease in human recipients of marrow from HL-Amatched sibling donors. Transplantation. 1974;18:295-304.

25. Hafsi S, Candido S, Maestro R, Falzone L, Soua Z, Bonavida B, Spandidos DA, Libra M. Correlation between the overexpression of Yin Yang 1 and the expression levels of miRNAs in Burkitt's lymphoma: a computational study. Oncol Lett. 2016;11:1021-5.

26. Havelange V, Garzon R. MicroRNAs: emerging key regulators of hematopoiesis. Am J Hematol. 2010;85:935-42.

27. He X, Chang Y, Meng F, Wang M, Xie Q, Tang F, Li P, Song Y, Lin J. MicroRNA-375 targets AEG-1 in hepatocellular carcinoma and suppresses liver cancer cell growth in vitro and in vivo. Oncogene. 2012;31:3357.

28. Henao-Mejia J, Williams A, Goff LA, Staron M, Licona-Limón P, Kaech SM, Nakayama M, Rinn JL, Flavell RA. The microRNA miR-181 is a critical cellular metabolic rheostat essential for NKT cell ontogenesis and lymphocyte development and homeostasis. Immunity. 2013;38:984-97.

29. Imai N, Kawabe M, Hikage T, Nojima T, Takahashi S, Shirai T. Effects on rat testis of 1.95-GHz W-CDMA for IMT-2000 cellular phones. Syst Biol Reprod Med. 2011;57:204-9.

30. Indrieri A, Carrella S, Carotenuto P, Banfi S, Franco B. The pervasive role of the miR-181 family in development, neurodegeneration, and cancer. Int J Mol Sci. 2020;21:2092.

31. Iravani Saadi M, Arandi N, Yaghobi R, Azarpira N, Geramizadeh B, Ramzi M. Aberrant expression of the miR-181b/miR-222 after hematopoietic stem cell transplantation in patients with acute myeloid leukemia. Indian J Hematol Blood Transfus Off J Indian Soc Hematol Blood Transfus. 2019;35:446-50.

32. Iravani Saadi M, Beigi MAB, Ghavipishe M, Tahamtan $M$, Geramizadeh B, Zare A, Yaghoobi R. The circulating level of interleukins 6 and 18 in ischemic and idiopathic dilated cardiomyopathy. J Cardiovasc Thorac Res. 2019;11:132.

33. Jiménez-Morales S, Miranda-Peralta E, Saldaña-Alvarez Y, Perez-Vera P, Paredes-Aguilera R, Rivera-Luna R, VelázquezCruz R, Ramírez-Bello J, Carnevale A, Orozco L. BCR-ABL, ETV6-RUNX1 and E2A-PBX1: prevalence of the most common acute lymphoblastic leukemia fusion genes in Mexican patients. Leuk Res. 2008;32:1518-22.

34. Jin HY, Oda H, Lai M, Skalsky RL, Bethel K, Shepherd J, Kang SG, Liu WH, Sabouri-Ghomi M, Cullen BR. MicroRNA-17 92 
plays a causative role in lymphomagenesis by coordinating multiple oncogenic pathways. EMBO J. 2013;32:2377-91.

35. Kanaan A, Cour I, Alvarez-Lafuente R, Benedicto M, Culebras E, Prats D, Fernandez C, Picazo JJ. Significance of nested PCR and quantitative real time PCR for cytomegalovirus detection in renal transplant recipients. Int J Antimicrob Agents. 2004;24:455-62.

36. Kantarjian H, Thomas D, O'Brien S, Cortes J, Giles F, Jeha S, Bueso-Ramos CE, Pierce S, Shan J, Koller C, Beran M, Keating M, Freireich EJ. Long-term follow-up results of hyperfractionated cyclophosphamide, vincristine, doxorubicin, and dexamethasone (Hyper-CVAD), a dose-intensive regimen, in adult acute lymphocytic leukemia. Cancer. 2004;101:2788-801.

37. Kaur P, Bartels C, Bentley H, Tsongalis G, editors. Select microRNA profiles of patients with chronic lymphocytic leukemia. New York: Laboratory Investigation, Nature Publishing Group; 2011.

38. Kazemi MJ, Yaghobi R, IravaniSaadi M, Geramizadeh B, Moayedi J. Association between TT virus infection and cirrhosis in liver transplant patients. Hepat Mon. 2015; 15:e28370.

39. Kebriaei P, Isola L, Bahceci E, Holland K, Rowley S, McGuirk J, Devetten M, Jansen J, Herzig R, Schuster M, Monroy R, Uberti J. Adult human mesenchymal stem cells added to corticosteroid therapy for the treatment of acute graft-versus-host disease. Biol Blood Marrow Transplant. 2009;15:804-11.

40. Kim JW, Mori S, Nevins JR. Myc-induced microRNAs integrate Myc-mediated cell proliferation and cell fate. Can Res. 2010;70:4820-8.

41. Kincaid RP, Burke JM, Cox JC, de Villiers E-M, Sullivan CS. A human torque teno virus encodes a microRNA that inhibits interferon signaling. PLoS Pathog. 2013;9:e1003818.

42. Kirtane K, Lee SJ. Racial and ethnic disparities in hematologic malignancies. J Am Soc Hematol. 2017;130:1699-705.

43. Landgraf P, Rusu M, Sheridan R, Sewer A, Iovino N, Aravin A, Pfeffer S, Rice A, Kamphorst AO, Landthaler M. A mammalian microRNA expression atlas based on small RNA library sequencing. Cell. 2007;129:1401-14.

44. Lee CW, Wohlan K, Dallmann I, Förster R, Ganser A, Krueger A. miR-181a expression in donor $\mathrm{T}$ cells modulates graft-versushost disease after allogeneic bone marrow transplantation. J Immunol. 2016;196:3927-34.

45. Li J, Ding Y, Huang Y, Chen W, Pan L, Li Y, Chen X, Chen Y, Wang S, Wu X. FAMLF is a target of miR-181b in Burkitt lymphoma. Braz J Med Biol Res. 2017;50:1-10.

46. Li Z, Huang H, Li Y, Jiang X, Chen P, Arnovitz S, Radmacher MD, Maharry K, Elkahloun A, Yang X, He C, He M, Zhang Z, Dohner K, Neilly MB, Price C, Lussier YA, Zhang Y, Larson RA, Le Beau MM, Caligiuri MA, Bullinger L, Valk PJM, Delwel R, Lowenberg B, Liu PP, Marcucci G, Bloomfield CD, Rowley JD, Chen J. Up-regulation of a HOXA-PBX3 homeobox-gene signature following down-regulation of miR-181 is associated with adverse prognosis in patients with cytogenetically abnormal AML. Blood. 2012;119:2314-24.

47. Lister T, Roberts M, Brearley R, Woodruff R, Greaves M. Prognostic significance of cell surface phenotype in adult acute lymphoblastic leukaemia. Cancer Immunol Immunother. 1979;6:227-30

48. Liu X, Liao W, Peng H, Luo X, Luo Z, Jiang H, Xu L. miR-181a promotes $\mathrm{G} 1 / \mathrm{S}$ transition and cell proliferation in pediatric acute myeloid leukemia by targeting ATM. J Cancer Res Clin Oncol. 2016;142:77-87.

49. Lu J, Getz G, Miska EA, Alvarez-Saavedra E, Lamb J, Peck D, Sweet-Cordero A, Ebert BL, Mak RH, Ferrando AA. MicroRNA expression profiles classify human cancers. Nature. 2005;435:834.

50. Marcucci G, Radmacher MD, Maharry K, Mrózek K, Ruppert AS, Paschka P, Vukosavljevic T, Whitman SP, Baldus CD,
Langer C, Liu C-G, Carroll AJ, Powell BL, Garzon R, Croce CM, Kolitz JE, Caligiuri MA, Larson RA, Bloomfield CD. MicroRNA expression in cytogenetically normal acute myeloid leukemia. N Engl J Med. 2008;358:1919-28.

51. Messmer BT, Albesiano E, Efremov DG, Ghiotto F, Allen SL, Kolitz J, Foa R, Damle RN, Fais F, Messmer D. Multiple distinct sets of stereotyped antigen receptors indicate a role for antigen in promoting chronic lymphocytic leukemia. J Exp Med. 2004;200:519-25.

52. Niu J, Xue A, Chi Y, Xue J, Wang W, Zhao Z, Fan M, Yang CH, Shao Z, Pfeffer LM. Induction of miRNA-181a by genotoxic treatments promotes chemotherapeutic resistance and metastasis in breast cancer. Oncogene. 2016;35:1302.

53. Okamoto H. History of discoveries and pathogenicity of TT viruses. Curr Top Microbiol Immunol. 2009;331:1-20.

54. Ouyang Y-B, Lu Y, Yue S, Giffard RG. miR-181 targets multiple Bcl-2 family members and influences apoptosis and mitochondrial function in astrocytes. Mitochondrion. 2012;12:213-9.

55. Ozguner M, Koyu A, Cesur G, Ural M, Ozguner F, Gokcimen A, Delibas N. Biological and morphological effects on the reproductive organ of rats after exposure to electromagnetic field. Saudi Med J. 2005;26:405-10.

56. Parikh A, Lee C, Joseph P, Marchini S, Baccarini A, Kolev V, Romualdi C, Fruscio R, Shah H, Wang F. microRNA-181a has a critical role in ovarian cancer progression through the regulation of the epithelial-mesenchymal transition. Nat Commun. 2014;5:2977.

57. Pekarsky Y, Santanam U, Cimmino A, Palamarchuk A, Efanov A, Maximov V, Volinia S, Alder H, Liu C-G, Rassenti L. Tcl1 expression in chronic lymphocytic leukemia is regulated by miR29 and miR-181. Can Res. 2006;66:11590-3.

58. Pons A, Nomdedeu B, Navarro A, Gaya A, Gel B, Diaz T, Valera S, Rozman M, Belkaid M, Montserrat E. Hematopoiesis-related microRNA expression in myelodysplastic syndromes. Leuk Lymphoma. 2009;50:1854-9.

59. Pui C-H, Crist WM. Cytogenetic abnormalities in childhood acute lymphoblastic leukemia correlates with clinical features and treatment outcome. Leuk Lymphoma. 1992;7:259-74.

60. Pui C-H, Robison LL, Look AT. Acute lymphoblastic leukaemia. Lancet. 2008;371:1030-43.

61. Pui C-H, Yang JJ, Hunger SP, Pieters R, Schrappe M, Biondi A, Vora A, Baruchel A, Silverman LB, Schmiegelow K. Childhood acute lymphoblastic leukemia: progress through collaboration. J Clin Oncol. 2015;33:2938.

62. Ramzi M, IravaniSaadi M, Zarei T, Yaghobi R, Arandi N. Association between cytotoxic T-lymphocyte antigen 4 gene polymorphisms and torque teno virus infection after hematopoietic stem cell transplantation. Exp Clin Transplant Off J Middle East Soc Organ Transplant. 2017;19:259-63.

63. Rezaei T, Amini M, Hashemi ZS, Mansoori B, Rezaei S, Karami H, Mosafer J, Mokhtarzadeh A, Baradaran B. MicroRNA-181 serves as a dual-role regulator in the development of human cancers. Free Radic Biol Med. 2020;152:432-54.

64. Rezahosseini O, Drabe CH, Sørensen SS, Rasmussen A, Perch M, Ostrowski SR, Nielsen SD. Torque-teno virus viral load as a potential endogenous marker of immune function in solid organ transplantation. Transplant Rev. 2019;33:137-44.

65. Rodriguez-Ortiz CJ, Baglietto-Vargas D, Martinez-Coria H, LaFerla FM, Kitazawa M. Upregulation of miR-181 decreases c-Fos and SIRT-1 in the hippocampus of 3xTg-AD mice. J Alzheimers Dis. 2014;42:1229-38.

66. Rowlings PA, Przepiorka D, Klein JP, Gale RP, Passweg JR, Henslee-Downey PJ, Cahn JY, Calderwood S, Gratwohl A, Socié G, Abecasis MM, Sobocinski KA, Zhang MJ, Horowitz MM. IBMTR severity index for grading acute graft-versus-host 
disease: retrospective comparison with Glucksberg grade. Br J Haematol. 1997;97:855-64.

67. Saadi MI, Arandi N, Yaghobi R, Azarpira N, Geramizadeh B, Ramzi M. Up-regulation of the miR-92a and miR-181a in patients with acute myeloid leukemia and their inhibition with locked nucleic acid (LNA)-antimiRNA; introducing c-kit as a new target gene. Int J Hematol Oncol. 2018;28:1-9.

68. Saadi MI, Arandi N, Yaghobi R, Azarpira N, Geramizadeh B, Ramzi M. Up-regulation of the miR-92a and miR-181a in patients with acute myeloid leukemia and their inhibition with locked nucleic acid (LNA)-antimiRNA; introducing c-kit as a new target gene. Int J Hematol Oncol. 2018;30:238-47.

69. Sang W, Zhang C, Zhang D, Wang Y, Sun C, Niu M, Sun X, Zhou C, Zeng L, Pan B, Chen W, Yan D, Zhu F, Wu Q, Cao J, Zhao K, Chen C, Li Z, Li D, Loughran TP Jr, Xu K. MicroRNA181a, a potential diagnosis marker, alleviates acute graft versus host disease by regulating IFN- $\gamma$ production. Am J Hematol. 2015;90:998-1007.

70. Schwind S, Maharry K, Radmacher MD, Mrózek K, Holland KB, Margeson D, Whitman SP, Hickey C, Becker H, Metzeler KH, Paschka P, Baldus CD, Liu S, Garzon R, Powell BL, Kolitz JE, Carroll AJ, Caligiuri MA, Larson RA, Marcucci G, Bloomfield CD. Prognostic significance of expression of a single microRNA, miR-181a, in cytogenetically normal acute myeloid leukemia: a cancer and leukemia group B study. J Clin Oncol. 2010;28:5257-64.

71. Shi L, Cheng Z, Zhang J, Li R, Zhao P, Fu Z, You Y. hsa-mir181a and hsa-mir-181b function as tumor suppressors in human glioma cells. Brain Res. 2008;1236:185-93.

72. Shin K-H, Bae SD, Hong HS, Kim RH, Kang MK, Park N-H. miR-181a shows tumor suppressive effect against oral squamous cell carcinoma cells by downregulating K-ras. Biochem Biophys Res Commun. 2011;404:896-902.

73. Song L, Liu H, Gao S, Jiang W, Huang W. Cellular microRNAs inhibit replication of the H1N1 influenza A virus in infected cells. J Virol. 2010;84:8849-60.

74. Song M-Y, Pan K-F, Su H-J, Zhang L, Ma J-L, Li J-Y, Yuasa Y, Kang D, Kim YS, You W-C. Identification of serum microRNAs as novel non-invasive biomarkers for early detection of gastric cancer. PLoS ONE. 2012;7:e33608.

75. Stolzenburg LR, Harris A. The role of microRNAs in chronic respiratory disease: recent insights. Biol Chem. 2018;399:219-34.
76. Sun X, Sit A, Feinberg MW. Role of miR-181 family in regulating vascular inflammation and immunity. Trends Cardiovasc Med. 2014;24:105-12.

77. Taylor MA, Sossey-Alaoui K, Thompson CL, Danielpour D, Schiemann WP. TGF- $\beta$ upregulates miR-181a expression to promote breast cancer metastasis. J Clin Investig. 2013;123:150-63.

78. Velu CS, Chaubey A, Phelan JD, Horman SR, Wunderlich M, Guzman ML, Jegga AG, Zeleznik-Le NJ, Chen J, Mulloy JC, Cancelas JA, Jordan CT, Aronow BJ, Marcucci G, Bhat B, Gebelein B, Grimes HL. Therapeutic antagonists of microRNAs deplete leukemia-initiating cell activity. $\mathrm{J}$ Clin Invest. 2014;124:222-36.

79. Visone R, Veronese A, Balatti V, Croce CM. MiR-181b: new perspective to evaluate disease progression in chronic lymphocytic leukemia. Oncotarget. 2012;3:195.

80. Visone R, Veronese A, Rassenti LZ, Balatti V, Pearl DK, Acunzo M, Volinia S, Taccioli C, Kipps TJ, Croce CM. miR-181b is a biomarker of disease progression in chronic lymphocytic leukemia. Blood J Am Soc Hematol. 2011;118:3072-9.

81. Wang G, Zhao R, Zhao X, Chen X, Wang D, Jin Y, Liu X, Zhao C, Zhu Y, Ren C. MicroRNA-181a enhances the chemotherapeutic sensitivity of chronic myeloid leukemia to imatinib. Oncol Lett. 2015;10:2835-41.

82. Wu C, Gong Y, Yuan J, Zhang W, Zhao G, Li H, Sun A, Zou Y, Ge J. microRNA-181a represses ox-LDL-stimulated inflammatory response in dendritic cell by targeting c-Fos. J Lipid Res. 2012;53:2355-63.

83. Xie W, Li Z, Li M, Xu N, Zhang Y. miR-181a and inflammation: miRNA homeostasis response to inflammatory stimuli in vivo. Biochem Biophys Res Commun. 2013;430:647-52.

84. Zhao L, Chen S, Yang P, Cao H, Li L. The role of mesenchymal stem cells in hematopoietic stem cell transplantation: prevention and treatment of graft-versus-host disease. Stem Cell Res Ther. 2019;10:1-13.

85. Zhao J, Gong A-Y, Zhou R, Liu J, Eischeid AN, Chen X-M. Downregulation of PCAF by miR-181a/b provides feedback regulation to TNF- $\alpha$-induced transcription of proinflammatory genes in liver epithelial cells. J Immunol. 2012;188:1266-74.

Publisher's Note Springer Nature remains neutral with regard to jurisdictional claims in published maps and institutional affiliations. 